\title{
SYNTHESIS AND REACTIONS OF \\ HALOGENATED POLYETHERS AND POLYSULFIDES
}

\author{
by \\ Melvin P. Zussmana, Jenn S. Shihb, \\ Douglas A. Wicks and David A. Tirreilc \\ Polymer Science and Engineering Department \\ University of Massachusetts \\ Amherst, MA 01003
}

\footnotetext{
a Present address: Westinghouse Research and Development Center, Pittsburgh, PA

b Present address: GAF Corporation, Wayne, NJ

c To whom correspondence should be addressed
} 
Introduction. Polyepichlorohydrin (PECH) is well known as a reactive elastomer. Displacenient at the carbon-chlorine bond of PECH has been accomplished with a wide variety of nucleophilic reagents, for the purposes of polymer modification, grafting and crossinking $(1,2)$. On the other hand, the PECH structure ( $(\boldsymbol{\sim})$ is hardly optimal from the point of view of its reactivity

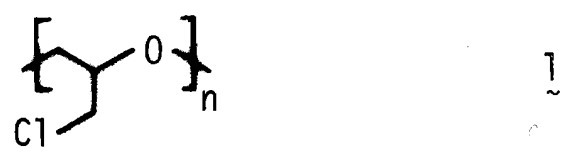

as a substrate for nucleophilic substitution: chloride is modest in its leaving group ability, and the B-branch point (i.e. the chain backbone) would be expected to depress reaction rates by a factor of 10 or so (3).

Within the past several years, we have examined the synthesis and reactions of several classes of polymers related to PECH. Wh have adopted three simple approaches to the preparation of polymeric substrates more reactive than PECH toward nucleophilic substitution. We have: i). removed the B-branch point by extension of the side chain, $i i)$. replaced the chloride leaving group by a more reactive bromide and $i i i)$. replaced the backbone oxygen atom by a sulfur atom that offers substantial anchimeric assistance to nucleophilic displacenient. Each of these simple structural changes affords elastomeric polymers more reactive than PECH toward attack by nucleophilic species. Wesent in this chapter an overview of the synthesis and reactions of these new reactive polymers.

Side Chain Extension. The repeating unit structure of $\mathrm{PECH}$ would suggest that the reactivity of the polymer would be rather similar to that of isobutyl chloride. The R-oxygen atom would not be expected to offer substantial anchimeric assistance in nucleophilic displacement, and should perhaps be mildly deactivating as a result of a small inductive effect (4). In general, the reactivity of isobutyl halides toward nucleophilic reagents is depressed in 
comparison with the reactivity of primary, straight-chain analogues.

Streitwieser lists comparative data for nine reactions of isobutyl and 1-propyl halides (3); within this set, kpropyl/kisobutyl ranges from 4.3 (for $\mathrm{RBr}+\mathrm{Cl}^{-}$in acetone) to 33.8 (for $\mathrm{Rl}^{+} \mathrm{Br}^{-}$in acetone).

The 6-branch point present in $\mathrm{PECH}$ is absent in polymers of higher 1,2epoxy- $\omega$-chloroalkanes. Such polymers are readily prepared by treatment of the neat monomers with the modified triethylaluniinum catalyst introduced by Vandenberg $(5,6)$; results for (2-chloroethyl)oxirane, (3-chloropropyl)oxirane and $(4$-chlorobutyl)oxirane $(\underset{\sim}{2 a}-\underset{\sim}{\sim})$ are summarized in Table $\mathbf{I}(7,8)$.

$$
\begin{aligned}
\underset{\sim}{2} \underset{\sim}{a}: & n=2 \\
\underset{\sim}{\mathbf{b}}: & n=3 \\
\underset{\sim}{c}: & n=4
\end{aligned}
$$

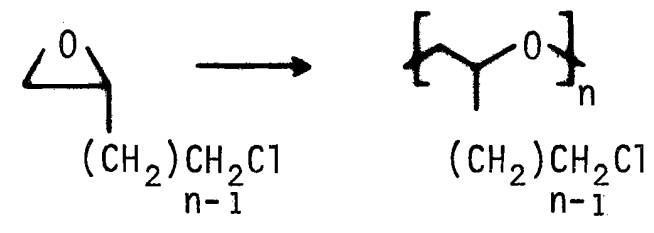

\begin{tabular}{|c|c|c|c|c|}
\hline Monomer & $\begin{array}{l}\text { Polymerizationa } \\
\text { Time (Days) } \\
\end{array}$ & Yield (\%) & $\left\{\begin{array}{l}\operatorname{linh}^{b} \\
(\mathrm{dL} / \mathrm{g})\end{array}\right.$ & $\mathrm{Tg}\left({ }^{\circ} \mathrm{C}\right)$ \\
\hline$\underset{\sim \sim}{2 a}$ & 14 & 89 & $4.12^{C}$ & -27 \\
\hline$\underset{\sim \sim}{\mathrm{b}}$ & 14 & 78 & $3.44^{C}$ & -42 \\
\hline$\underset{\sim \sim}{2 c}$ & 10 & 77 & 1.21 & -50 \\
\hline
\end{tabular}

TABLE I

HOMOPOLYMERIZATION OF (CHLOROALKYL)OXIRANES

a Polymerization at room temperature in presence of 5 mol-\% A1Et3/ $\mathrm{H}_{2} \mathrm{O}$ / acetylacetone $(1 / 0.5 / 0.5)$

b In $\mathrm{CHCT}_{3}, 0.5$ wt $\%, 35^{\circ} \mathrm{C}$

c GPC peak molecular weight $>106$

In each case, the polymer is obtained as a white elastomer of high molecular weight ( $>10^{6}$ in some experiments). Each of these polymers is soluble in 
benzene, in chlorinated hydrocarbons and in dipolar aprotic solvents. Figure 1 shows the kinetics of chloride substitution by tetra-n-butylammonium benzoate in $\mathrm{N}, \mathrm{N}$-dimethylacetamide at $50^{\circ} \mathrm{C}$, for $\mathrm{PECH}$ and for the polymers of $\underset{\sim}{2 a}-\underset{\sim}{\mathrm{C}}$. Under these conditions, each of the higher honiologues is about equally reactive, and all are converted to the benzoate more rapidly than PECH. Each of these reactions shows negative deviations from second-order kinetics, but second-order rate constants can be estimated from the initial reaction rates. This procedure gives a second-order rate constant of $3.9 \times 10^{-4} \mathrm{M}^{-1} \mathrm{~s}^{-1}$ for poly[2-chloroethy1)oxirane] and a value of $0.63 \times 10^{-4} \mathrm{M}^{-1} \mathrm{~s}^{-1}$ for $\mathrm{PECH}$. Thus the higher homologues are more reactive than $\mathrm{PECH}$ by a factor of 6 , an observation completely consistent with known structure-reactivity relations for simple alkyl halides.

The reactive carbon-chlorine bond in these polyethers allows their conversion to other interesting materials. For example, quantitative chloride displacement by benzoate anion followed by basic niethanolysis affords hydrophilic polyether elastomers that are water-soluble or water-swellable, depending on side chain length (9). Poly[(3-hydroxypropyl)oxirane] is a colorless elastomer that can be cast into tough, clear films from water or methanol. Poly[(4-hydroxybutyl)oxirane $]$ is insoluble in water, but quite hydrophilic; a film immersed in water gains $46 \%$ in weight in 90 min at room temperature, while retaining good mechanical integrity. Uses for such materials as adhesives, as biomaterials and as contact lenses may be anticipated.

Bromide as Leaving Group. Perhaps the most straightforward approach to increasing the reactivity of halogenated substrates--polymeric or otherwise-is to exploit the well known order of leaving group ability, i.e., $\mathrm{I}>\mathrm{Br}>\mathrm{Cl}>\mathrm{F}$. For example, data provided by Streitwieser suggest that 
replacement of chloride by bromide will lead to rate enhancements of 50 - to 200 -fold, depending on reaction conditions (3). One cannot take this approach too far in the design of reactive polymeric substrates, however, since the leaving group must be inert to the conditions of polymerization if protectiondeprotection schemes are to be avoided. The ideal leaving group would be cornpletely unreactive toward the nucleophilic species involved in chain growth, but readily displaced in subsequent polymer modification reactions.

Bromide appears to be useful in this regard. Table II summarizes our homopolymerization experiments on (2-bromoethyl)oxirane, (3-bromopropyl)oxirane and (4-bromobutyl)oxirane $(2 z-\mathcal{L})(10-12)$.
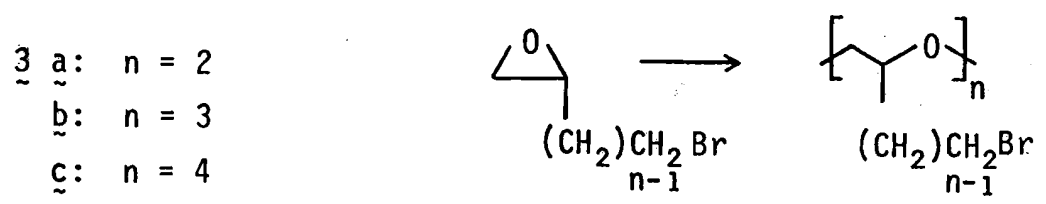

\section{TABLE II}

HOMOPOLYMERIZATION OF (BROMOALKYL) OXIRANES

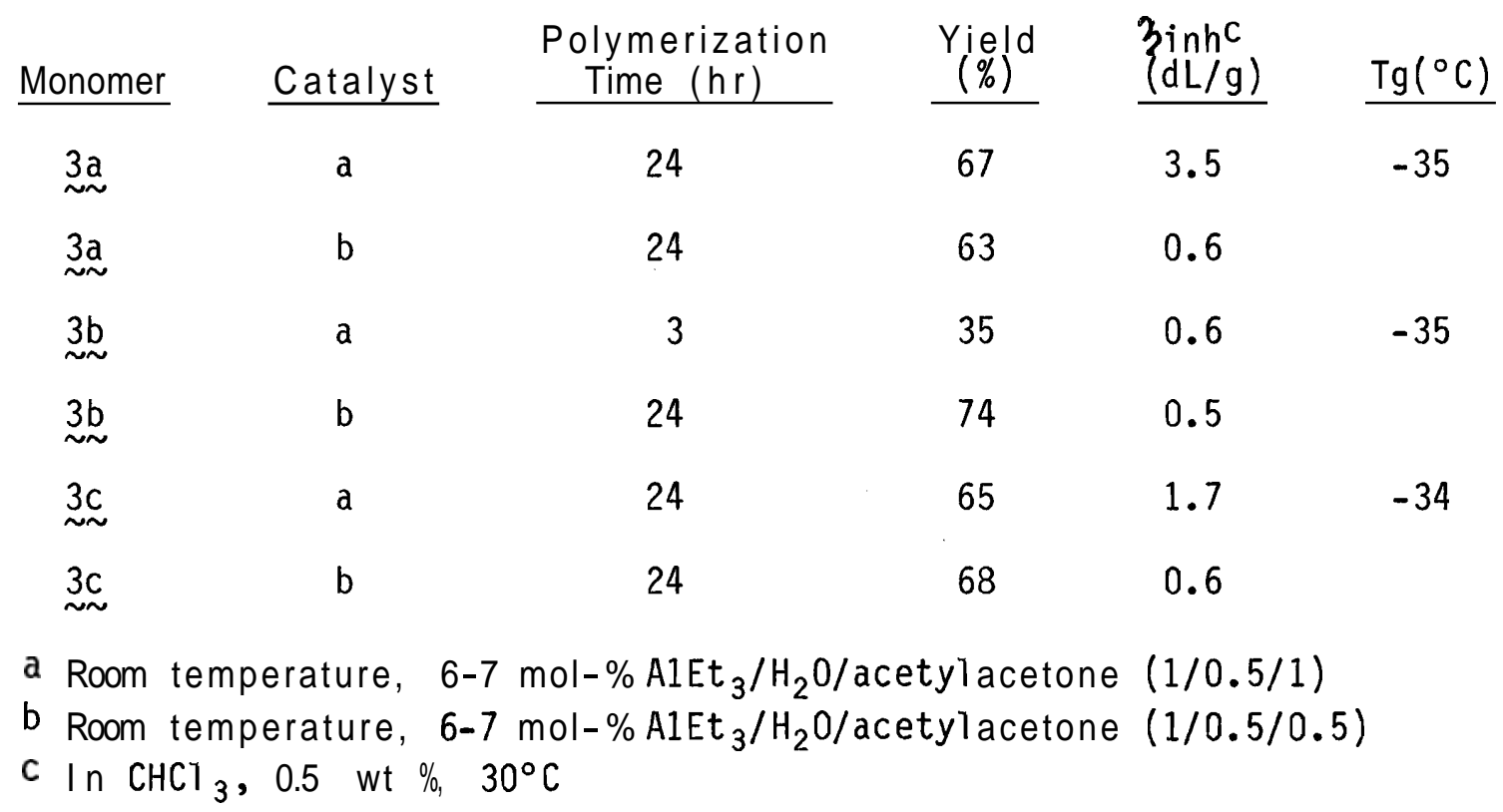


Polymerization of each of these oxiranes is effectively accomplished by treatment of the neat monomer with the chelated aluminum catalyst. It is interesting to note that higher molecular weights are generally realized by using the catalyst mixture that contains a $1: 1$ ratio of triethylaluminum and acetylacetone; this may be a result of chelation of the most acidic catalyst sites and a consequent reduction in chain transfer associated with Al-assisted ionization of the $\mathrm{C}-\mathrm{Br}$ bond. The poly[( $\omega$-bromoalkyl)oxirane]s are slightly tacky elastomers at room temperature; a11 undergo a glass transition at approxiniately $-35^{\circ} \mathrm{C}$.

Figure 2 shows the kinetics of bromide substitution by tetra-n-butylammonium benzoate in $\mathrm{CDCl}_{3}$ at $45^{\circ} \mathrm{C}$, for poly (epibromohydrin) (PEBH) and for the polymers of $\underset{\sim \sim}{3 a}-\underset{\sim}{\sim}$ Although these results are not directly comparable to those in Figure 1 because of differences in solvents and temperatures, qualitative consistency is apparent. First of all, each of the higher homologues is about equally reactive, and all react more rapidly than PEBH. The kinetics show negative deviation from second-order behavior, as before, but the initial slopes of the second-order plots are again useful for comparative purposes. Table III lists the rate constants obtained in this way. As in the chloride series, extension of the side chain by a single carbon atom removes the B-branch point and accelerates the reaction by a factor of about 10 . (The significance of the apparent two-fold higher reactivity of the 3-bromopropyl side chain compared to its 2- and 4-carbon homologues has not been determined.) Finally, the bromides are indeed more reactive than the chlorides; despite the use of $\mathrm{CDCl}_{3}$ as the reaction solvent, the bromides react more than an order of magnitude faster than the chlorides, even though the latter were converted in DMAc, a superior solvent for nucleophilic substitutions of this kind. 


\section{TABLE I I I}

KINETICS OF SUBSTITUTION ON POLY( $\omega$-BROMOALKYL)OXIRANES

Side Chain

Length

1

2

3

4
$\underline{\left[-\mathrm{CH}_{2} \mathrm{Br}\right]_{0}} \underline{\mathrm{b}}(\mathrm{M})$

$8.57 \times 10^{-3}$

$6.97 \times 10^{-3}$

$4.53 \times 10^{-3}$

$3.88 \times 10^{-3}$

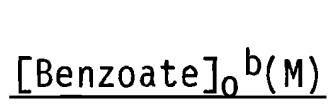

$1.74 \times 10^{-2}$

$1.40 \times 10^{-2}$

$9.11 \times 10^{-3}$

$8.10 \times 10^{-3}$
$\underline{\left(M^{-1} s^{-1}\right)}$

$0.8 \times 10^{-3}$

$8.2 \times 10^{-3}$

$19 \times 10^{-3}$

$7.9 \times 10^{-3}$

a $45^{\circ} \mathrm{C}, \mathrm{CDCl}_{3}$

b Initial Concentrations

c Initial slope of second-order kinetic plot

Anchimeric Assistance by Backbone Sulfur. The acceleration of halide displacement by neighboring sulfides is among the most familiar examples of anchimeric assistance in organic chemistry. Table IV illustrates the magnitude of the effect for primary alkyl chlorides (4).

TABLE IV

RELATIVE RATE CONSTANTS FOR HYDROLYSIS OF ALKYL CHLORIDESa

$$
\begin{array}{ll}
\multicolumn{1}{c}{\frac{\mathrm{RCl}}{\mathrm{krel}_{3} \mathrm{~b}}} \\
\mathrm{CH}_{3} \mathrm{CH}_{2} \mathrm{CH}_{2} \mathrm{CH}_{2} \mathrm{Cl} & 1.00 \\
\mathrm{CH}_{3} \mathrm{CH}_{2} \mathrm{OCH}_{2} \mathrm{CH}_{2} \mathrm{Cl} & 0.18 \\
\mathrm{CH}_{3} \mathrm{CH}_{2} \mathrm{SCH}_{2} \mathrm{CH}_{2} \mathrm{Cl} & 2750 \\
\mathrm{CH}_{3} \mathrm{CH}_{2} \mathrm{OCH}_{2} \mathrm{CH}_{2} \mathrm{CH}_{2} \mathrm{Cl} & 0.77 \\
\mathrm{CH}_{3} \mathrm{CH}_{2} \mathrm{SCH}_{2} \mathrm{CH}_{2} \mathrm{CH}_{2} \mathrm{Cl} & 1.00
\end{array}
$$

a Aqueous dioxane, $\left[\mathrm{H}_{2} \mathrm{O}\right]=20 \mathrm{M}, 100^{\circ} \mathrm{C}$

b Rate relative to 1-chlorobutane 
A B-sulfide accelerates the solvolysis nearly 3000 -fold compared to the simple aikyl ha1ide and approximately 15,000-fold compared to the B-chtoroether. On the other hand, the $\gamma$-sulfide offers no assistance; apparently closure to the four-membered cyclic sulfonium ion cannot compete with direct displacement by the external nucleophile.

These results suggest that poly[(chloromethyl)thiirane] (PCMT, A) should be substantially more reactive than polyepichlorohydrin toward nucleophilic

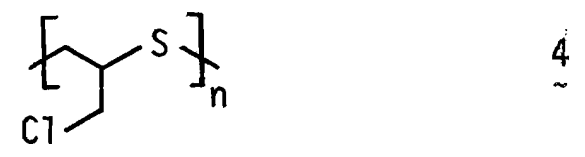

substitutions, and indeed it is (13). In addition, the formation of the intermediate episulfonium ion by neighboring group displacement leads to a rearrangement of the $\mathrm{OMT}$ repeating unit to one $(\underset{\sim}{5})$ derived from the ringopening polymerization of 3-chlorothietane (3CT, Scheme I) (13-17).

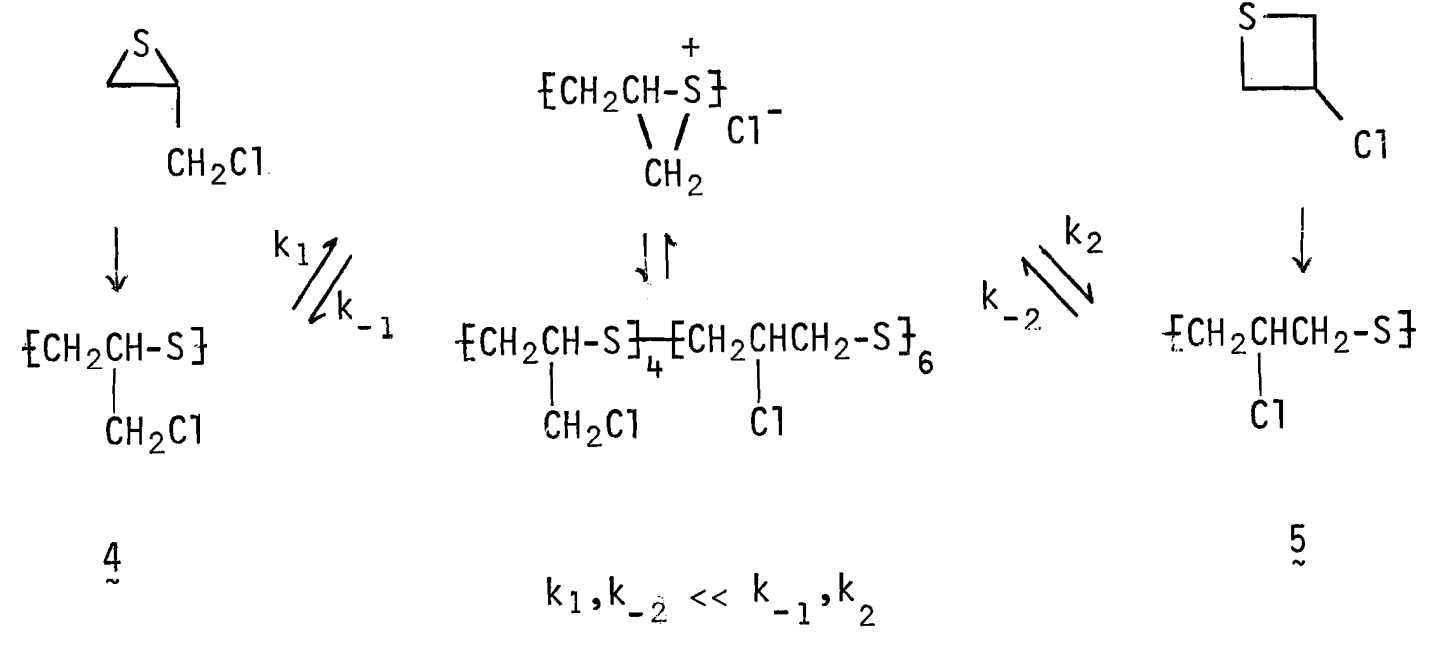


We have examined the effects of concentration, temperature, solvent and added electrolyte on the kinetics of this structural interconversion. In at instances, the kinetics are well described by the rate law for a reversible first-order reaction [Eq 1]:

$$
\left(K+K^{-}\right) t=\ln \left[\frac{f_{0}(3 C T)-f_{\infty}(3 C T)}{f(3 C T)-f_{\infty}(3 C T)}\right]
$$

where $f(3 C T)$ is the fraction of 3 -chlorothietane repeating units in the copolymer and the subscripts 0 and o refer to initial and equilibrium copolymer structures, respectively; $K$ and $K^{-}$are combinations of the elementary rate constants $k_{1}, k_{2}, k_{-1}$ and $k_{-2}$ (cf. Scheme I) such that

$$
K=\frac{k_{1} k_{2}}{k_{-1}+k_{2}}
$$

and

$$
k^{-}=\frac{k_{-1} k_{-2}}{k_{-1}+k_{2}}
$$

The quantity $(K+K-)$ is thus obtained as the slope of a plot of the right side of Eq 1 versus time, and because

$$
f(3 C T)_{\infty}=\frac{K}{K+K^{-}}
$$

the composite rate constants $K$ and $K^{-}$can be determined individually. Each of these quantities ( $K$ and $K^{-}$) may be viewed as a rate constant for cyclization, multiplied by a factor that describes the partitioning of the sulfonium ion intermediate between the two isomeric products of chloride ion attack. Table $V$ summarizes the values of $(K+K-)$ obtained in this way: 
TABLE V

KINETICS OF REPEATING UNIT ISOMERIZATION

IN POLY[(CHLOROMETHYL)THIIRANE] AND POLY(3-CHLOROTHIETANE)

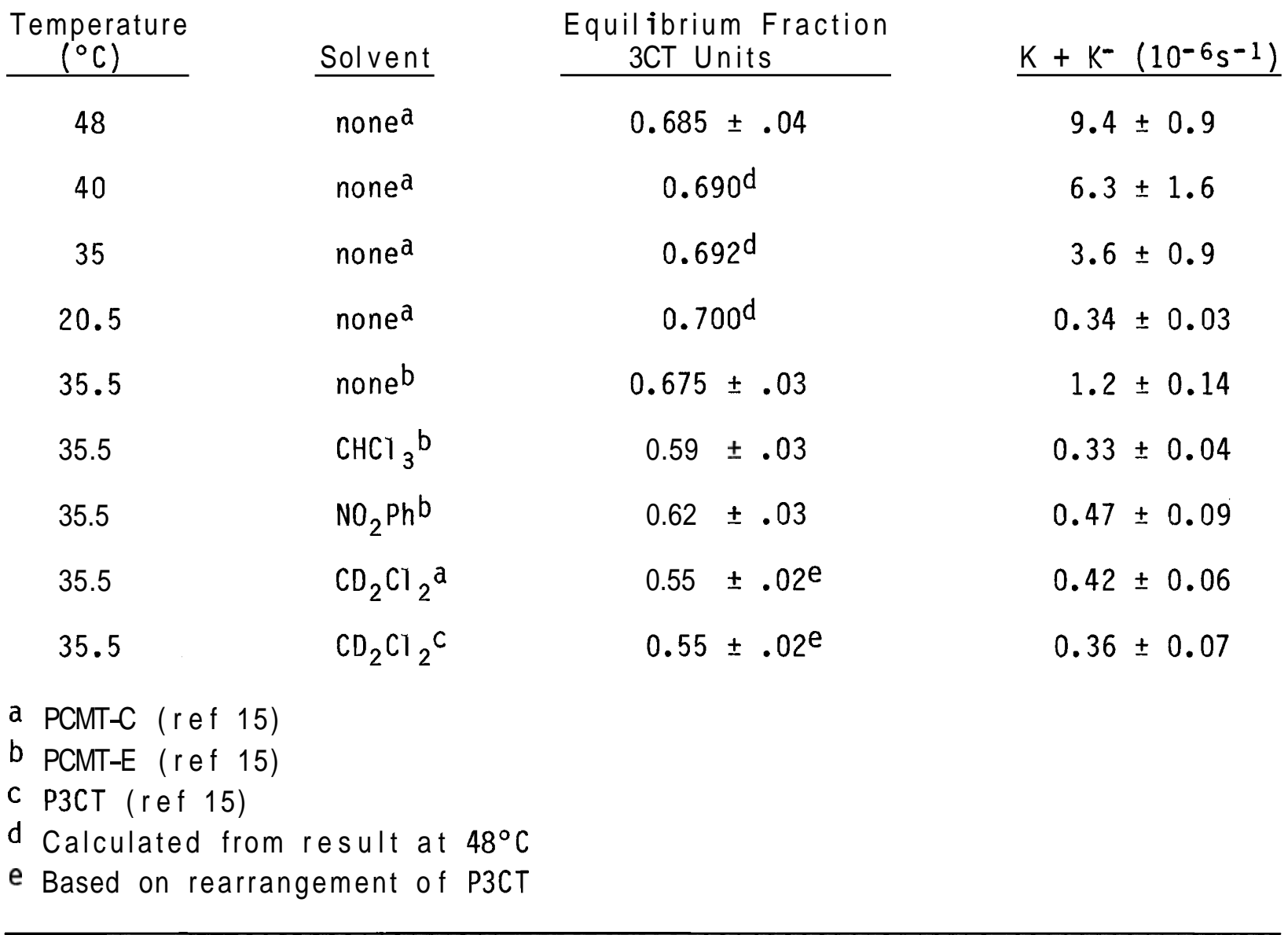

These data reveal several interesting features of the repeating unit isomerization. First of all, the rate constants are of roughly the same order of magnitude as those observed in solvolyses and rearrangements of B-chiorosulfides of low molecular weight when differences in solvents and temperatures are taken into account. Table VI provides a summary of comparative data from the literature. We have also determined the apparent rate constant for the analogous isomerization of 1-chloro-2-ethylthiopropane (Z) to 2-chloro-1ethylthiopropane $\underset{\sim}{(8)}$ to be $4 \times 10^{-6} s^{-1}$ at $45^{\circ} \mathrm{C}$ in the absence of solvent. The 
latter is of course a composite rate constant of the kind defined by Equations 2 and 3 .

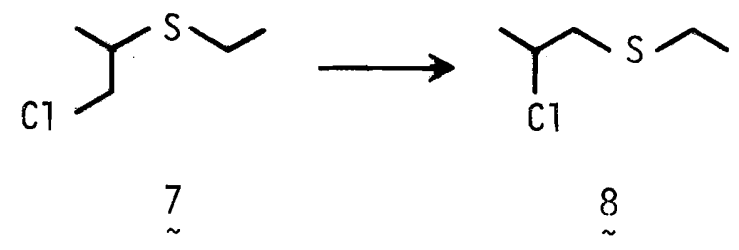

TABLE V I

RATES AND ACTIVATION ENERGIES OF REACTIONS OF B-CHLOROSULFIDES

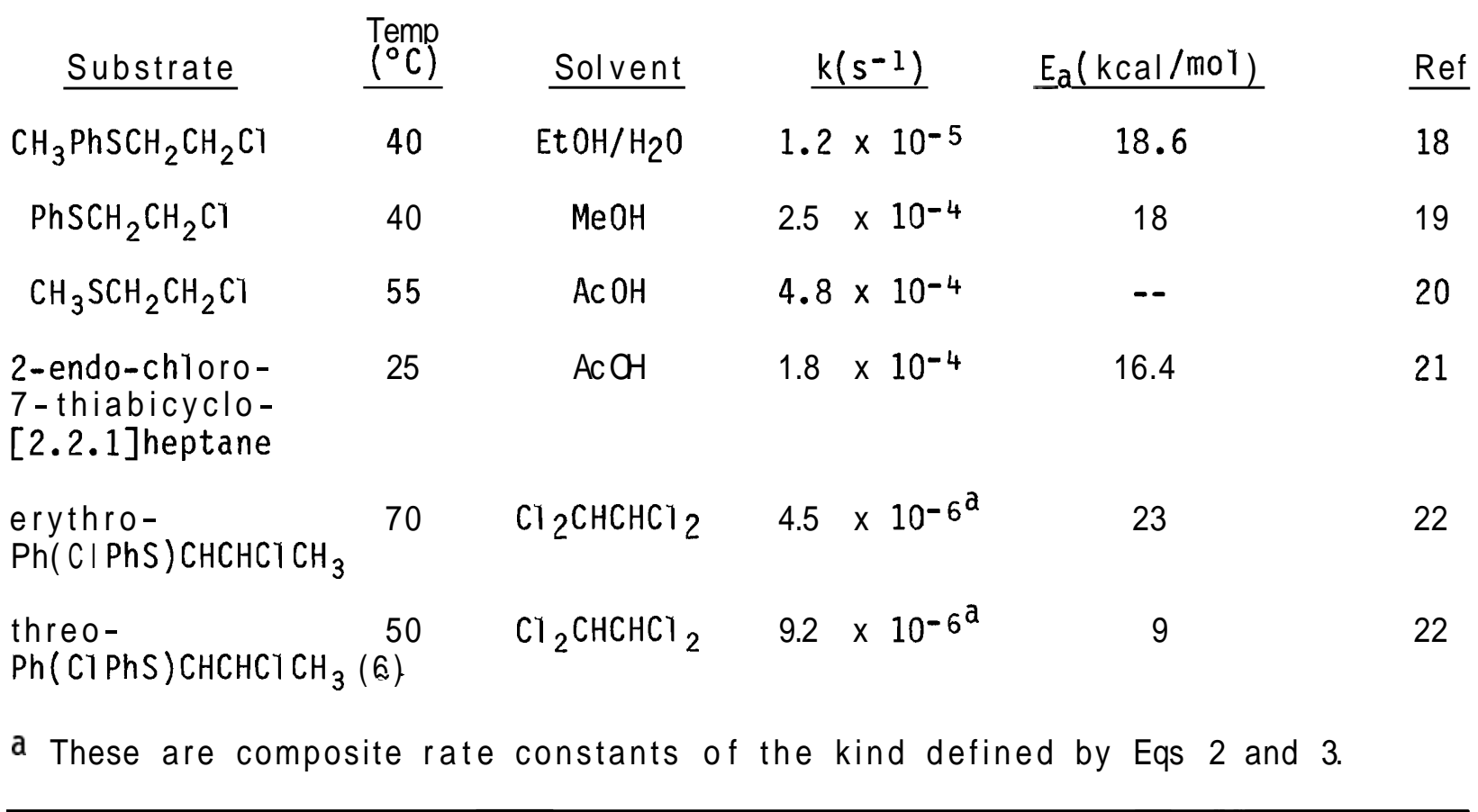

A second point of interest is the apparent activation energy of the isomerization. From an examination of the temperature dependences of $K$ and $K$ - for reaction in the bulk polymer, we find apparent activation energies of $22-23 \mathrm{kcal} / \mathrm{mol}$ for each of the forward and reverse processes. Given the composite nature of $K_{\text {and }} K^{-1}$, these are true activation energies only if the partitioning of the sulfonium ion intermediate is insensitive to temperature. 
Nonetheless, the similarity of these parameters to those Tisted in Table VI argues for a common mechanism that involves in all instances rate-determining ring-closure to the episulfonium ion, as suggested by Scheme I- The sole exception is the low activation energy for rearrangement of threo- $\underset{\sim}{\sim}$ this behavior appears to be anomalous, and no explanation is provided by the original authors (22).

The solvent dependence of the reaction rate is also consistent with this mechanistic scheme. Comparison of the rate constants for isomerizations of PCMT in chloroform and in nitrobenzene shows a small (ca. 40\%) rate enhancement in the latter solvent. Simple electrostatic theory predicts that nucleophilic substitutions in which neutral reactants are converted to ionic products should be accelerated in polar solvents (23), so that a rate increase in nitrobenzene is to be expected. In fact, this effect is often very small (24). For example, Parker and co-workers (25) report that the $S_{N} 2$ reaction of methyl bromide and dimethyl sulfide is accelerated by only $50 \%$ on changing the solvent from $88 \%(\mathrm{~W} / \mathrm{W})$ methanol-water to $\mathrm{N}, \mathrm{N}$-dimethylacetamide (DMAC) at low ionic strength; this is a far greater change in solvent properties than that investigated in the present work. Thus a smal1, positive dependence of reaction rate on solvent polarity is implicit in the sulfonium ion mechanism.

A final observation consistent with rate-determining cyclization is that the reaction rate is relatively insensitive to added electrolyte. Addition of 0.5 equivalents of tetra-n-butylammonium chloride or tetra-n-butylammonium azide to chloroform solutions of PCMT produces very small, and approxiniately equal, increases in rate. Alternative reaction mechanisms that invoke as ratedetermining steps either i). attack by chloride ion, or ii). unassisted $S_{N} 1$ dissociation of the carbon-chlorine bond are inconsistent with this result. 
Repeating Unit Isomerization vs. Isomerization Polymerization. Repeating unit isomerization is similar in several respects to isomerization polymerization $(26,27)$. Isomerization polymerization may be defined as a process whereby a monomer of structure $A$ is converted to a polymer of repeating unit structure $B$, wherein the conversion of $A$ to $B$ represents a structural change more substantial than simple ring opening or double bond addition:

$$
n A \longrightarrow f t_{n}
$$

The product of an isomerization polymerization is thus determined by the relative rates of the propagation and isomerization steps; i.e., it is kinetically determined. If isomerization is much faster than propagation, the homopolymer of $B$ is obtained; competitive rates will lead to A-B copolymers.

We define repeating unit isomerization as a process subsequent to polymerization, in which an intramolecular rearrangement of the repeating unit leads to a thermodynamically preferred structure:

$$
n A \longrightarrow(A)_{n} \longrightarrow(A)_{x}+B t_{y}
$$

Thus propagation must be much faster than isomerization, and the product will be determined by thermodynamics, rather than by reaction kinetics. The net results of the two processes may be quite similar, however, in that polymers of unexpected structures may be obtained, and copolymers may be prepared by polymerization of a single monomer.

\section{ACKNOWLEDGMENTS}

This work was supported by grants from the Polymers Program of the National Science Foundation. Support of our research by an NSF Presidential. Young Investigator Award is also gratefully acknowl edged. 


\section{REFERENCES}

1. E. Schacht, D. Bailey and 0. Vogl, J. Polym. Sci. Polym. Chem. Ed. 16, 2343 (1978) and references therein.

2. E J. Vandenberg, in C.C. Price and E J. Vandenberg, Eds. Coordination Polymerization, Plenum, 1983, p. 11.

3. A Streitwieser, Jr., Solvolytic Displacement Reactions, McGraw-Hill, New York, 1962.

4. H. Bohme and K Sell, Chem. Ber., 81, 123 (1948).

5. E J. Vandenberg, J. Polym. Sci. 47, 486 (1960).

6. E.J. Vandenberg, J. Polym. Sci. A17, 525 (1969).

7. J.S. Shih, J.F. Brandt, M.P. Zussman and DA Tirrell, J. Polym. Sci. Polym. Chem. Ed. 20, 2839 (1982).

8. J.S. Shih, Ph.D. Dissertation, Carnegie-Mellon University, 1984.

9. J.S. Shih and DA. Tirrell, J. Polym. Sci. Polym. Chem. Ed. 22, 781 (1984).

10. J.S. Shih and D.A. Tirrell, J. Macromol. Sci. Chem. A21, 1013 (1984).

11. S. Vaze and D.A. Tirrell, J. Bioactive and Compatible Polym. 1, 79 (1986).

12. D.A Wicks and D.A. Tirrell, Polym. Prepr. 27(2), 21 (1986).

13. M.P. Zussman and D.A. Tirrell, Macromolecules 14, 1148 (1981).

14. M.P. Zussman and DA. Tirrell, Polymer Bull. 7, 439 (1982).

15. M.P. Zussman and D.A. Tirrell, J. Polym. Sci. Polym. Chern. Ed. 21, 1417 (1983).

16. M.P. Zussman, Ph. D. dissertation, Carnegie-Mellon University, 1982.

17. M.P. Zussman and DA. Tirrell, submitted for pubtication.

18. R. Bird and C.J.M. Stirling, J. Chem. Soc. Perkin II, 1221, 1973.

19. F.G. Bordwell and W.T. Brannen, Jr., J. Am. Chem. Soc. 86, 4645 (1964).

20. I- Tabushi, Y. Tamaru and Z Yoshida, Bull. Chem. Soc. Japan 47, 1455 (1974) . 
21. I. Tabushi, Y. Tamaru, Z. Yoshida and T. Sugimoto, J. Am. Chem. Soc. 97, 2886 (1975).

22. G.H. Schmid and V. Csizmadia, Can. J. Chem. 50, 2465 (1972).

23. R.W. Alder, R. Baker and JM. Brown, Mechanism in Organic Chemistry, Wiley, New York, 1971, p. 43.

24. A.J. Parker, Chem. Rev. 69, 1 (1969).

25. Y.C. Mac, WA Millen, A.J. Parker and D.W. Watts, J. Chem. Soc. (B), 525 (1967).

26. J. P. Kennedy and R.M. Thomas, Makromol. Chem. 53, 28 (1962).

27. J.P. Kennedy in H.F. Mark, N.G. Gaylord and NM. Bikales, Eds., Encyclopedia of Polymer Science and Technology, Wiley, New York, 1967, Vo1. 7, p. 754 . 


\section{FIGURE CAPTIONS}

Fig. 1. Conversion versus time for substitution by tetrabutylammonium benzoate on poly(epichlorohydrin) (A, A, separate runs); poly[(2chloroethyl)oxirane] (ه); poly[(3-chloropropyl)oxirane] (v); and poly[(4-chlorobutyl)oxirane] (O).

Fig. 2. Conversion versus time for substitution by tetrabutylammonium benzoate on poly(epibrornohydrin) (+); poly[(2-bromoethyl)oxirane] (o); poly[(3-bromopropyl)oxirane] (A); and poly[(4-bromobuty1)oxirane] (ㅁ) . 


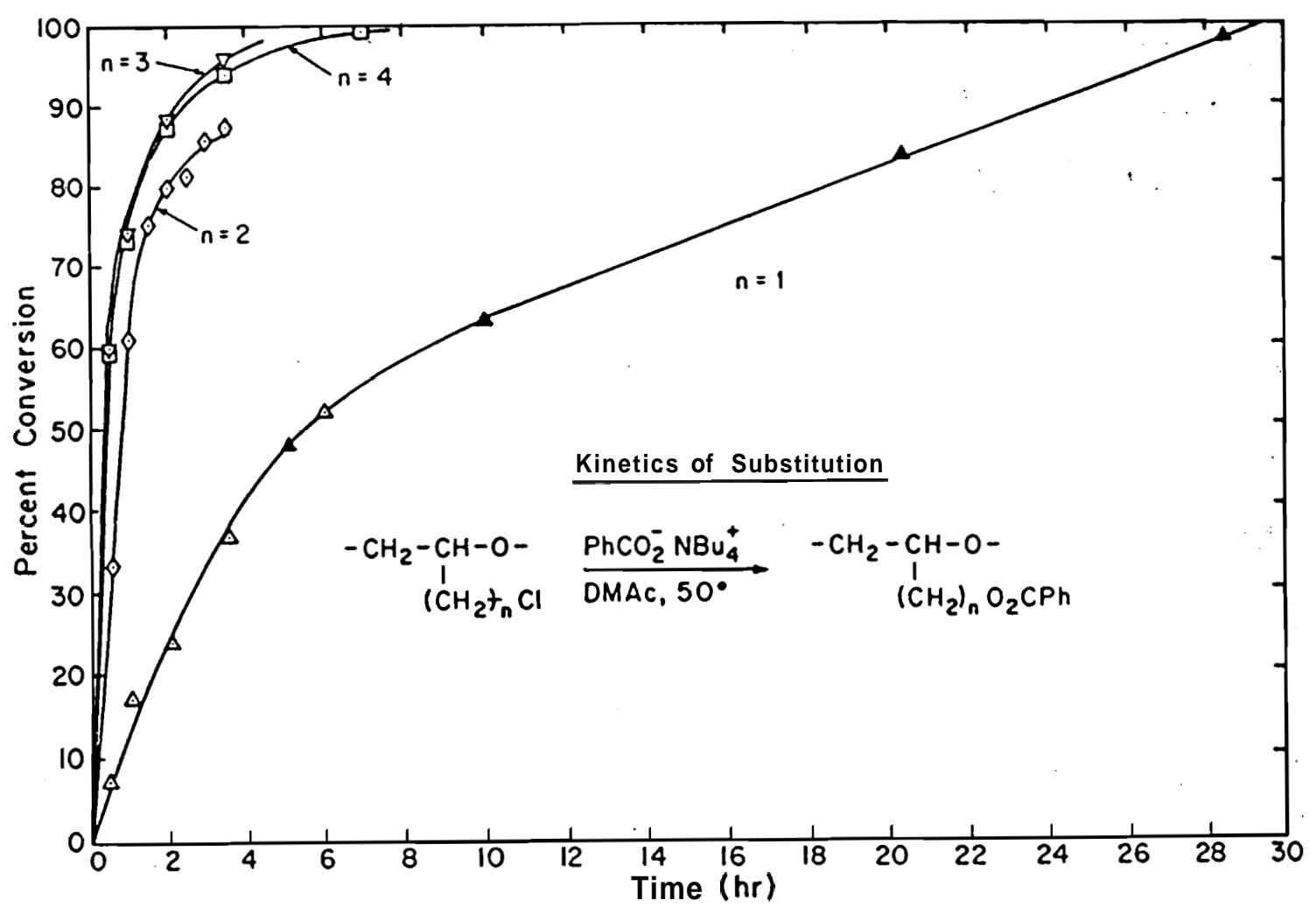

Fig. 1

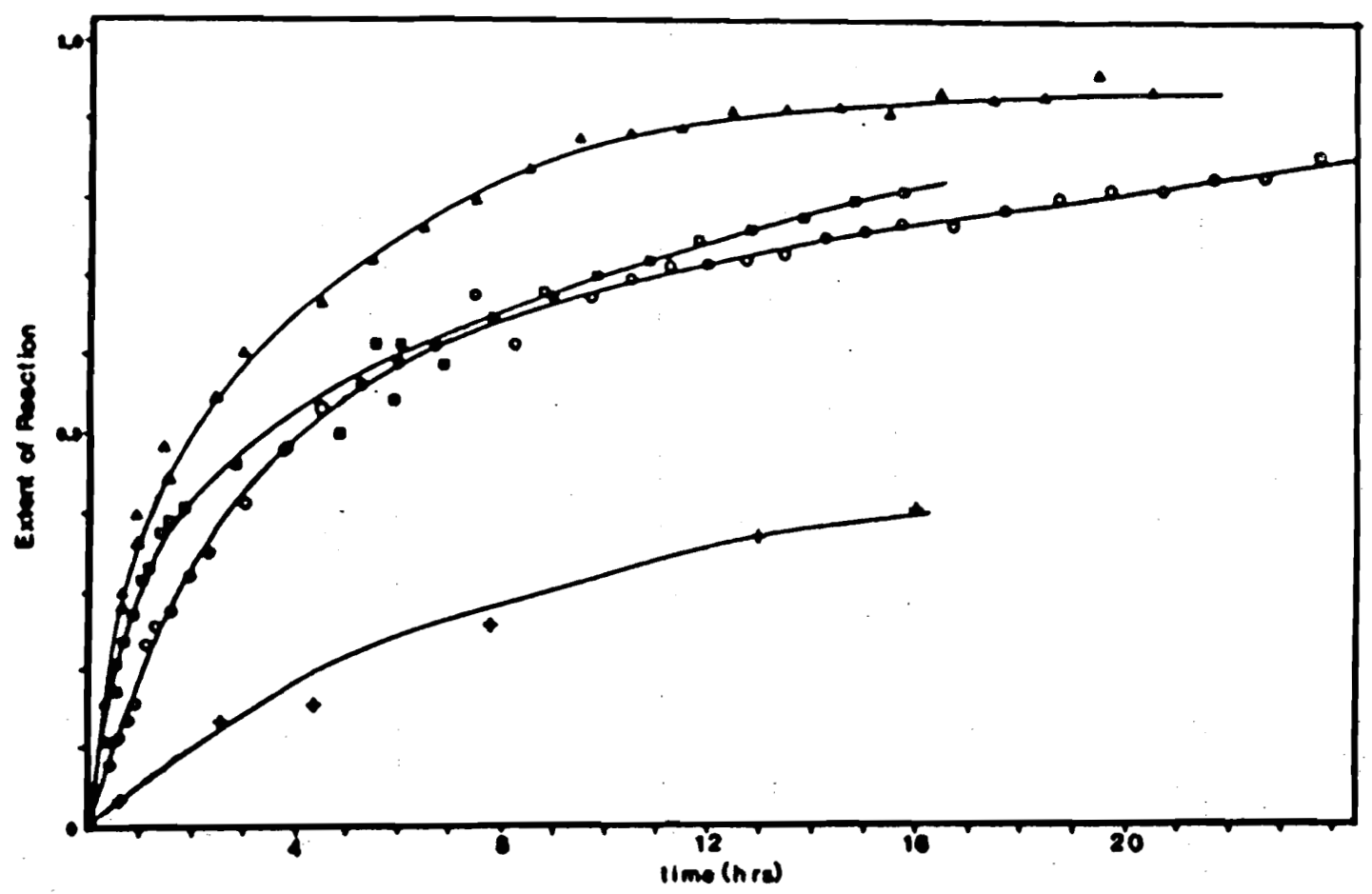

Fig. 2 